\title{
Methanol extract of smokeless tobacco alters inflammation and nociception process in animal models
}

\author{
Siddig I Abdelwahab ${ }^{1 *}$, Syam Mohan ${ }^{2}$, Manal ME Taha ${ }^{2}$, Mohammed Al Bratty ${ }^{1,3}$, \\ Waquar Ahsan ${ }^{1,3}$, Hassan A Alhazmi, ${ }^{1,3}$ \\ ${ }^{1}$ Smokeless Tobacco Research Group, Substance Abuse Research Centre, ${ }^{2}$ Medical Research Centre, ${ }^{3}$ Department of \\ Pharmaceutical Chemistry, College of Pharmacy, Jazan University, Jazan, Saudi Arabia
}

*For correspondence: Email: siddigroa@yahoo.com, siddigabdelwahab.sarc@gmail.com; Tel: +966 506612390

\begin{abstract}
Purpose: To investigate the inflammatory and nociceptive alterations due to the use of Nicotiana tabacum or smokeless tobacco (MEST) owing to the fact that it is used by some people to relieve dental pain.

Methods: Hepatic biochemical indicators and thiobarbituric acid reactive substances assay were used to assess MEST toxicity and pharmacological doses selection. The effects on inflammation of different pharmacological doses (100, 200 and $500 \mathrm{mg} / \mathrm{kg}$ i.p.) of MEST were evaluated using xylene-induced ear edema and cotton pellet granuloma tests. Indomethacin (10 mg/kg, i.p.) was used as positive standard drug, whereas the vehicle $0.5 \%$ CMC treated group was considered as negative control. Acetic acid-induced abdominal contraction test and formalin-induced hind paw licking model were utilized to assess the role of MEST in nociception. Indomethacin (10 mg/kg i.p.) and diclofenac sodium (10 mg/kg i.p.) were used as positives standard drugs. The vehicle used was $0.5 \%$ CMC which served as the negative control.

Results: MEST (50 \%, $200 \mathrm{mg} / \mathrm{kg})$ and indomethacin (47.5 \%) both elicited a significant $(p<0.001)$ anti-edematogenic effect on xylene-induced ear edema. MEST also showed a significant $(p<0.001)$ inhibitory effect on granuloma formation at all administered doses as compared to the untreated groups which was comparable to standard drug indomethacin. The number of acetic acid induced writhings was observed to be significantly increased $(p<0.001)$ by MEST at all doses, unlike diclofenac that led to significant reduction $(p<0.001)$ in the number of writhings, when compared to the untreated group. MEST also showed a significant $(p<0.05)$ dose-dependent reduction of the hind paw licking caused by formalin when compared to the vehicle control.

Conclusion: These results signify that administration of MEST induces inflammatory and nociceptive alterations. However, the extract is not recommended for dental pain due to its other toxic effects that have previously been reported.
\end{abstract}

Keywords: Nicotiana tabacum, Smokeless tobacco, Inflammation, Nociception

This is an Open Access article that uses a funding model which does not charge readers or their institutions for access and distributed under the terms of the Creative Commons Attribution License (http://creativecommons.org/licenses/by/4.0) and the Budapest Open Access Initiative (http://www.budapestopenaccessinitiative.org/read), which permit unrestricted use, distribution, and reproduction in any medium, provided the original work is properly credited.

Tropical Journal of Pharmaceutical Research is indexed by Science Citation Index (SciSearch), Scopus, International Pharmaceutical Abstract, Chemical Abstracts, Embase, Index Copernicus, EBSCO, African Index Medicus, JournalSeek, Journal Citation Reports/Science Edition, Directory of Open Access Journals (DOAJ), African Journal Online, Bioline International, Open-J-Gate and Pharmacy Abstracts

\section{INTRODUCTION}

Consumption of Nicotiana tabacum L., (Solanaceae) or Tobacco has been linked to various human ailments including cancer [1]. Smokeless tobacco (ST) is a chewable form of tobacco that is placed in the oral cavity $[1,2]$. Tobacco plants have various botanical 
taxonomies and has different names in various cultures and communities specially Sudan, Yemen and Saudi Arabia. In Sudan, about $40 \%$ of males and $10 \%$ of females use Tombak (local name of ST) [3,4]. Nowadays, the trafficking of ST is illegal in several countries such as Saudi Arabia, Japan, Australia and New Zealand [5]. Toxicity of these tobacco species and their health impacts are expected to be reasonably different. Our previous findings revealed that the extracts of Sudanese and Saudi ST posed different in vitro hepatotoxicities [6]. There are more than 5,000 identified chemicals present in tobacco, and out of these, 55 have been evaluated as showing 'sufficient evidence for carcinogenicity' in either laboratory animals or humans. Tobacco contains carcinogens like polycyclic aromatic hydrocarbons, aldehydes and nitrosamines which are metabolically activated by hydrolysis, reduction, or oxidation by xenobiotic metabolism through phases I and II enzymes [7].

The mortality burden attributed to tobacco use is believed to be influenced by inflammation, which might promote cancer development and progression [8]. Inflammation is the body's effort of self-defense to eliminate damaging stimuli and commence the healing procedure. It is an element of the body's immune response. Acute inflammation is required for the healing process in response to infections, wounds, and any damage to tissue. Interfering with the normal functions of the body in regard to inflammation is always a concern for toxic agents.

Various reports have shown that ST interferes with inflammation pathways when tested using in vitro models $[9,10]$. The use of ST augmented the receptiveness to periodontal disease which is distinguished by extreme lymphoproliferation, plasma cell development and cytokine production $[11,12]$. Inflammatory profile analysis revealed the differences in cytokine expression between smokers, moist snuff users, and dual users when compared to non-tobacco consumers [13]. In vitro exposure of immune cells to nicotine caused decreased levels of IFN-y and interleukin-2 (IL-2) [14]. Smokeless tobacco extract is reported to decrease IL-12 production from LPS-stimulated and increase it from IFN- $\gamma$-stimulated macrophages [15].

To the best of our knowledge, no in vivo animal models have been utilized to assess the effects of ST on the natural inflammatory and nociception processes. Therefore, the present study was carried out to evaluate the effects of methanol extract of smokeless tobacco (MEST) on animal models of inflammation and nociception.

\section{EXPERIMENTAL}

\section{Tobacco sample and extraction procedure}

Smokeless tobacco (ST) powder was obtained from exclusive supplier in Jazan, Saudi Arabia. Identification of the sample was conducted in Substance Abuse and Toxicology Research Centre, Jazan University, Jazan, Saudi Arabia. A measured quantity $(500 \mathrm{~g})$ of ST powder was extracted with $600 \mathrm{~mL}$ of methanol thrice and the combined extracts were filtered through a Whatman® No. 41 filter paper (pore size, 20 - 25 $\mu \mathrm{m})$. Further filtration was achieved by $0.22 \mu \mathrm{m}$ MILLEX and the filtrate was dried under vacuum using a rotary evaporator and stored at $4{ }^{\circ} \mathrm{C}$ until required.

\section{Acute toxicity study and dose selection}

Adult male and female Sprague Dawley rats (6 8 weeks old; 150 - $180 \mathrm{~g}$ ) were obtained from the Experimental Animal House $(E A H)$, Jazan University. The animals were given standard rat pellets and tap water ad libitum. Forty eight rats were divided equally into four groups. The negative control group received only vehicle 0.5 $\%$ CMC whereas the three treated groups were divided on the basis of doses given. Treated group animals were treated with MEST at doses of 100,200 and $500 \mathrm{mg} / \mathrm{kg}$ i.p. and kept under observation for 14 days. Animals were foodfasted overnight prior dosing and for further 3 to $4 \mathrm{~h}$ after dosing. Animals were then observed at $0.5,2,4,8,24$ and $48 \mathrm{~h}$ for the onset of clinical or toxicological symptoms. Mortality, if any, was observed over a period of two weeks. Animals were then sacrificed on the $15^{\text {th }}$ day. Biochemical parameters (SGOT, SGPT and alkaline phosphatase) were determined using standard methods [16]. This study was approved by the Ethics Committee for Animal Experimentation at our institute (Research Ethics Committee, Substance Abuse Research Centre, Jazan University, Jazan; approval number: SARC.EC.82). All animals received human care according to the criteria outlined in the "Guide for the Care and Use of laboratory Animals" prepared by the National Academy of Sciences and published by the National Institute of Health.

\section{Thiobarbituric acid reactive substances assay}

Thiobarbituric acid reactive substances (TBARS) assay was used to measure malondialdehyde (MDA), an indicator of lipid peroxidation [17]. Briefly, $10 \%(\mathrm{w} / \mathrm{v})$ liver homogenate in $0.1 \mathrm{~mol} / \mathrm{L}$ PBS was centrifuged at $4{ }^{\circ} \mathrm{C}$ for $10 \mathrm{~min}$. Two millilitres of supernatant, $0.67 \%$ 2-thiobarbituric 
acid and $20 \%$ trichloroacetic acid solution, were heated on a water-bath $\left(95^{\circ} \mathrm{C}\right)$ for $30 \mathrm{~min}$. The tubes were then centrifuged and the supernatants obtained were analyzed to determine MDA concentrations spectrophotometrically at $532 \mathrm{~nm}$. The results are expressed as MDA nmol/mg.

\section{Xylene-induced ear edema test}

Animals were divided into five groups of either sex. MEST $(100,200$ and $500 \mathrm{mg} / \mathrm{kg}$ ) and standard drug indomethacin $(10 \mathrm{mg} / \mathrm{kg})$ were intraperitoneally injected into rats $30 \mathrm{~min}$ before the application of xylene $(20 \mu \mathrm{L})$ to the anterior and posterior surfaces of the right ear [18]. The left ear was considered as control. Two hours after xylene application, animals were sacrificed by cervical dislocation and both ears were removed. Circular sections were taken, using a cork borer with a diameter of $7 \mathrm{~mm}$, and weighed. The increase in weight caused by the irritant was measured by subtracting the weight of the untreated left ear section from that of the treated right ear sections.

\section{Cotton pellet granuloma test}

Granulomatous lesions were induced by surgically implanting two cotton pellets subcutaneously in the dorsal region of the rats, one near each axilla of either female or male rats [17]. Thiopental sodium ( $25 \mathrm{mg} / \mathrm{kg}$, i.p.) was used as anesthetic agent and back of the rats were aseptically shaved. MEST was orally administered at three different doses $(100,200$ or $500 \mathrm{mg} / \mathrm{kg}$ ) respectively by using $0.5 \%$ carboxy methyl cellulose (CMC) as vehicle. After twenty minutes, sterilized pellets of cotton $(7 \pm$ $0.5 \mathrm{mg}$ ) were subcutaneously inserted in the interscapular distance on the previously shaved back. The rats of the negative control group were administered with the same volume of vehicle, whereas the positive group animals received indomethacin $(10 \mathrm{mg} / \mathrm{kg}$ i.p.). Rats were sacrificed on the eighth day and the pellets surrounded by granuloma tissue were dissected out carefully and dried at $70{ }^{\circ} \mathrm{C}$. Mean weight of the granuloma tissue formed around each pellet was recorded. The pellets were weighed in both moist and dry states.

\section{Formalin test}

Formalin test was utilized to examine the analgesic (antinociceptive) effect of MEST [18]. Swiss albino mice (20-30 g) were divided into different groups of either sex. Control group received the vehicle, test groups were injected with different doses of MEST $(100,200$ or 500 $\mathrm{mg} / \mathrm{kg}$ i.p.) and the standard group was injected with diclofenac $(10 \mathrm{mg} / \mathrm{kg}$ i.p.). $30 \mathrm{~min}$ after injection of MEST, standard or the vehicle, $20 \mu \mathrm{L}$ of sterile formalin ( $5 \%$ ) was injected into the right back paw of rats using a Hamilton syringe and the animals were directly placed in the formalin test container. The time spent in licking and biting the injected leg immediately after formalin injection was recorded at intervals. The time spent in the first $5 \mathrm{~min}$ was considered as the first phase (early phase) of pain and that during 15 to $30 \mathrm{~min}$ as the second phase (late phase). The time interval from 5 to $15 \mathrm{~min}$ is the painless phase of the formalin test.

\section{Acetic acid-induced abdominal contraction test}

The antinociceptive property of MEST was further investigated by using the model of writhing response in both male and female Swiss albino mice $(20-30 \mathrm{~g})$ as per the standard protocol [19]. The writhing pattern was induced by an intraperitoneal injection of $0.7 \%$ acetic acid at a dose of $0.1 \mathrm{~mL} / 10 \mathrm{~g}$ body weight. MEST samples $(100,200$ and $500 \mathrm{mg} / \mathrm{kg})$, standard diclofenac $(10 \mathrm{mg} / \mathrm{kg})$ and control vehicle $(0.5 \%$ $\mathrm{CMC}$ ) were intraperitoneally injected into the mice $30 \mathrm{~min}$ before the administration of acetic acid, and the number of writhes produced after 5 min of the administration was noted for a period of $15 \mathrm{~min}$.

\section{Statistical analysis}

One-way analysis of variance (ANOVA) was used to determine a significant difference between the control group and experimental groups. $p<0.01$ was set as statistically significant. The analytical data were analyzed using SPSS statistical program 20.0 (IBM SPSS, Armonk, NY).

\section{RESULTS}

The acute toxicity of MEST was tested on female and male rats by measuring the concentrations of ALP, AST, ALT and MDA. Comparison of tissue MDA in MEST-treated rats with healthy rats indicated a significant modulation in MDA level after the induction of oxidative stress $(p<$ 0.001 ). Significant effect on lipid peroxidation was observed amongst all treated groups in a dose independent manner as no significant differences were observed between low and high doses of MEST amongst male and female rats. All results for MDA levels are compared in Figure 1. The effects of MEST on various biochemical parameters in the groups under study are given in Table 1. Treatment with MEST showed a 


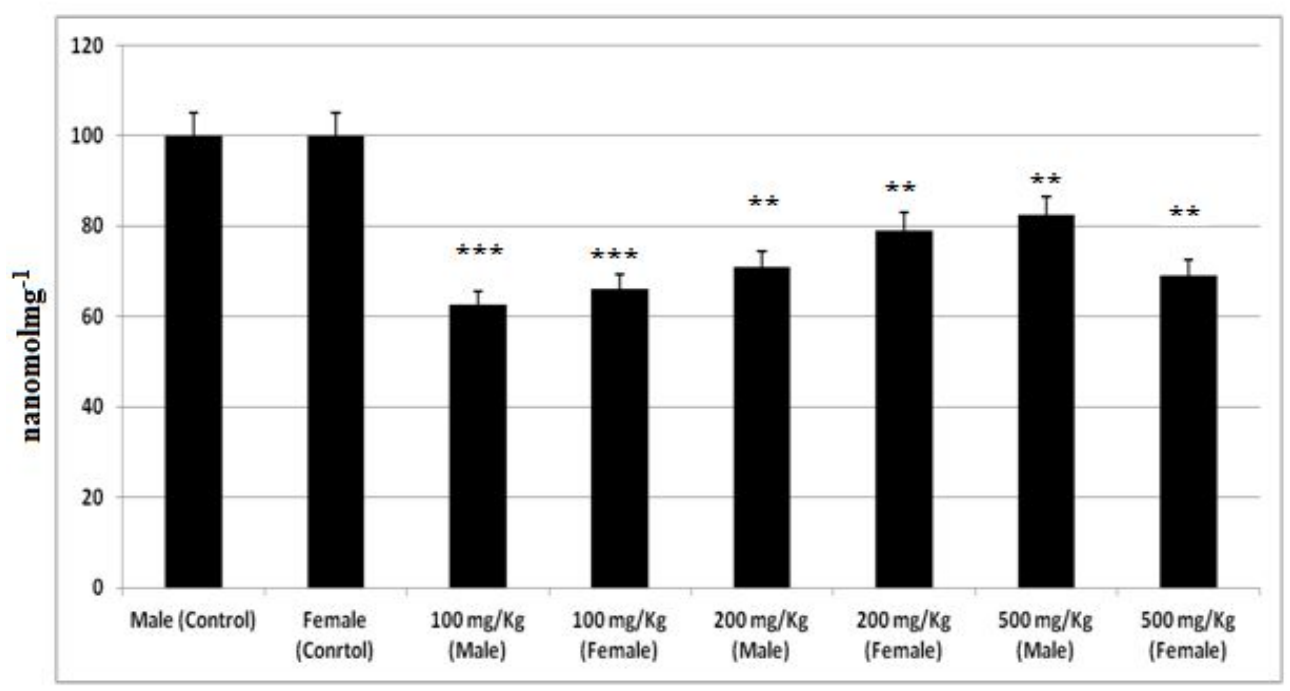

Figure 1: The effect of treatment with MEST on MDA level in rats' liver homogenate. The bar signs on top of the columns indicate mean \pm standard deviation $(\mathrm{n}=6) ;{ }^{* *} p<0.01 ;{ }^{* * *} p<0.001$

Table 1: Acute toxicity parameters of the effect of MEST on male and female rats

\begin{tabular}{lccc}
\hline Group & \multicolumn{3}{c}{ Parameter } \\
\cline { 2 - 4 } & SGOT (U/mL), AST & SGPT (U/mL), ALT & Alkaline phosphatase (U/mL) \\
\hline Male (Control) & $110 \pm 1.7$ & $82 \pm 1.3$ & $79 \pm 1.6$ \\
Female (Control) & $111 \pm 2.9$ & $79 \pm 5.8$ & $83 \pm 2.5$ \\
MEST 100 mg/kg (Male) & $72.5 \pm 5.1^{* *}$ & $51.5 \pm 5.4^{* *}$ & $58.5 \pm 0.82^{* *}$ \\
MEST $100 \mathrm{mg} / \mathrm{kg}$ (Female) & $74.5 \pm 3.8^{* *}$ & $59 \pm 4.6$ & $71.5 \pm 0.4$ \\
MEST $200 \mathrm{mg} / \mathrm{kg}$ (Male) & $79.5 \pm 5.9^{* *}$ & $61 \pm 3.8$ & $63.5 \pm 0.19$ \\
MEST 200 $\mathrm{mg} / \mathrm{kg}$ (Female) & $72.5 \pm 2.7^{* *}$ & $56 \pm 1.4^{* *}$ & $63 \pm 0.62^{* *}$ \\
MEST 500 mg/kg (Male) & $74.5 \pm 2.2^{* *}$ & $51.5 \pm 1.2^{* *}$ & $69.5 \pm 0.81$ \\
MEST 500 $\mathrm{mg} / \mathrm{kg}$ (Female) & $57 \pm 1.8^{* *}$ & $65.5 \pm 2.5^{* *}$ & $68 \pm 1.4$ \\
\hline${ }^{* *} p<0.01^{* * *} p<0.001$ & & &
\end{tabular}

${ }^{* *} p<0.01 ;{ }^{* * *} p<0.001$

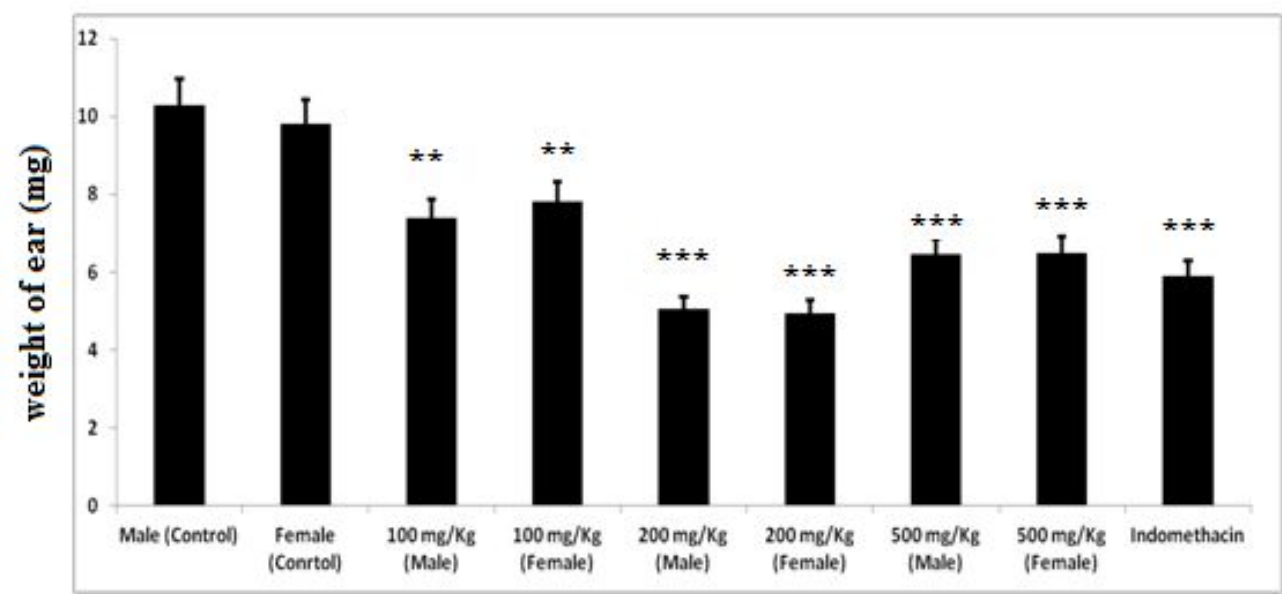

Figure 2: Effects of MEST on xylene-induced ear edema in male and female rats; ${ }^{* *} p<0.01 ;{ }^{* * *} p<0.001$; compared to control

significant $(p<0.001)$ decrease in ALT, AST and ALP levels with maximum decrease in SGOT enzyme at a dose of $500 \mathrm{mg} / \mathrm{kg}$ in the female group (57 $\pm 1.8 \mathrm{U} / \mathrm{mL})$.

The effect of MEST on xylene-induced ear edema is depicted in Figure 2. MEST at doses of
200 and $500 \mathrm{mg} / \mathrm{kg}$ in both male female animals decreased the ear edema rate by more than 50 $\%$ which was comparable to that of indomethacin (47.5\%). Both MEST and indomethacin elicited a significant antiedematogenic effect on xylene induced ear edema $(p<0.001)$ and inhibited the ear edema markedly compared to the control. 


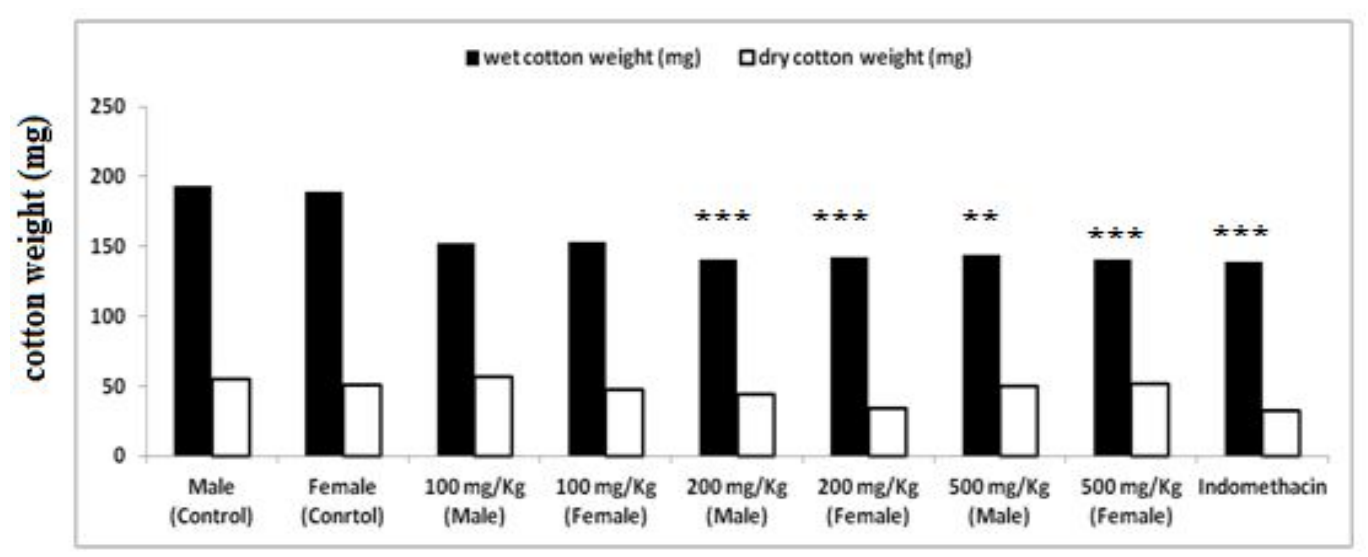

Figure 3: Chronic anti-inflammatory activity of MEST in cotton pellet granuloma test in rats; ${ }^{* *} p<0.01 ;{ }^{* * *} p<$ 0.001; compared to control

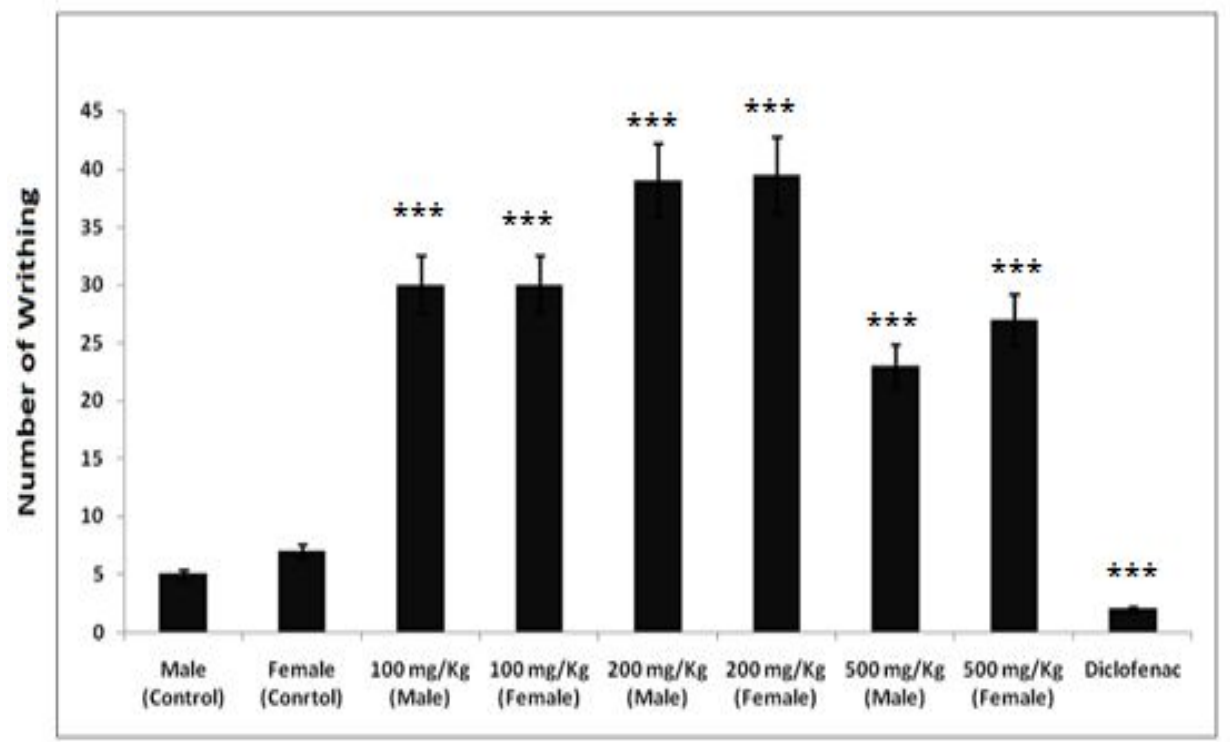

Figure 4: Analgesic activity of standard diclofenac and MEST in acetic acid writhing test. Values are represented in mean $\pm \mathrm{SEM} ;{ }^{* * *} p<0.001$; compared to control

To investigate the anti-inflammatory activity of the MEST extract and its effects on the proliferative phase of inflammation, cotton pellet granuloma formation test was used and the results are presented in Figure 3. Granulomatous lesions were successfully induced by surgical implantation of cotton pellets in the dorsal region of the rats, one near each axilla of either female or male rats. The MEST at a dose level of 100 , 200 and $500 \mathrm{mg} / \mathrm{kg}$ showed a significant inhibitory effect on granuloma formation and was comparable to the standard drug indomethacin. MEST significantly $(p<0.001)$ reduced both dry and wet weights of the granuloma. Statistically significant reduction in both forms was recorded at most of the tested doses of MEST.

The effect of MEST on acetic acid induced writhing is presented in Figure 4. MEST at doses of 100,200 and $500 \mathrm{mg} / \mathrm{kg}$ produced highly significant $(p<0.001)$ augmentation in the number of writhings produced by acetic acid in mice when compared to untreated group. This observation was independent of the animal's sex. Diclofenac produced highly significant $(p<$ 0.001) reduction in the number of writhings produced by acetic acid in mice when compared to untreated group.

The results of the effect of the MEST against formalin-induced hind paw licking in mice are shown in Table 2. The MEST pre-administered male and female animals showed a significant ( $p$ $<0.05$ ) dose-dependent reduction of the hind paw licking caused by formalin when compared with vehicle control. All doses of MEST extract showed remarkable percentages of inhibition that was comparable to the standard drug diclofenac sodium. 
Table 2: Effect of MEST against formalin-induced hind paw licking in mice

\begin{tabular}{lcccc}
\hline Group & Early phase (s) & Inhibition (\%) & Late phase (s) & Inhibition (\%) \\
\hline Male (Control) & $42 \pm 1.5$ & - & $60 \pm 2.6$ & - \\
Female (Control) & $39 \pm 2.1$ & - & $64 \pm 2.8$ & - \\
MEST 100 mg/kg (Male) & $6 \pm 0.92^{*}$ & 85.7 & $7.3 \pm 0.13^{*}$ & 87.8 \\
MEST 100 mg/kg (Female) & $6.45 \pm 1.7^{*}$ & 83.4 & $6.55 \pm 0.04^{*}$ & 89.7 \\
MEST $200 \mathrm{mg} / \mathrm{kg}$ (Male) & $10 \pm 0.56$ & 76.1 & $2.45 \pm 0.08^{* *}$ & 95.9 \\
MEST 200 mg/kg (Female) & $10.8 \pm 0.94$ & 72.3 & $3.25 \pm 0.14^{* *}$ & 94.9 \\
MEST 500 mg/kg (Male) & $6.6 \pm 0.47^{*}$ & 84.2 & $2.15 \pm 0.09^{*}$ & 96.4 \\
MEST 500 mg/kg (Female) & $5.65 \pm 0.63^{*}$ & 85.5 & $1.85 \pm 0.11^{*}$ & 89.6 \\
Diclofenac sodium 10 mg/kg & $4.2 \pm 0.04^{* *}$ & 89.5 & $1.80 \pm 0.04^{* *}$ & 97.0 \\
\hline
\end{tabular}

${ }^{*} p<0.05$; ${ }^{* *} p<0.01$; compared to control

\section{DISCUSSION}

The present study was designed to assess the anti-inflammatory and antinociceptive properties of MEST using established animals models of inflammation and pain. To the best of our knowledge, no in vivo animal models have been utilized to assess the effects of MEST on the natural inflammation and pain process. The effect of MEST was also tested on biochemical indicators and oxidative stress in rats to obtain the suitable doses to be administered in animals. Decrease in the antioxidant defense system and liver toxicity of ST has been previously reported. It has also been shown that the experimental dosing of ST extract induces an enhanced induction of hepatic lipid peroxidation and DNA damage [20,21].

Two animal models of inflammation have been employed in this study, namely, xylene-induced ear edema and cotton pellet granuloma tests. Both MEST and standard drug indomethacin elicited a significant antiedematogenic effect on xylene-induced ear edema $(p<0.001)$. Moreover, the extract at a dose level of 100, 200 and $500 \mathrm{mg} / \mathrm{kg}$ showed a significant inhibitory effect on granuloma formation. As we know, xylene-induced edema is usually utilized to assess the levels of vasodilatation and plasma extravasations of neurogenic inflammation. In this assay, treatment with MEST (100 $500 \mathrm{mg} / \mathrm{kg}$ ) considerably reduced the ear edema in a dose-dependent manner. The inhibition of ear edema indicated that MEST attenuated vasodilatations and plasma extravasations of neurogenic inflammation, which were vital in controlling the early stage of acute inflammation. In cotton pellet-induced granuloma formation model, the cotton implant dry weight was used to evaluate the granuloma formation. The mechanism of effective drugs on this chronic model of inflammation involves inhibitory activity on macrophage activation, infiltration, and aggregation. In the current study, pretreatment with MEST showed a dose-dependent decrease in granuloma formation, and effectiveness was observed to be comparable with standard drug indomethacin. Modulation of cyclooxygenase-2 by ST was previously reported $[22,23]$. This may be attributed to the presence of flavanoids present in ST as the flavanoids are known for their antioxidant and anti-inflammatory activities.

Traditionally, ST is used on infants to reduce the pain linked with erupting teeth [22]. In the present study, male and female animals pre-administered with MEST showed a significant $(p<0.05)$ dosedependent reduction of the hind paw licking induced by formalin when compared with vehicle control. All doses of MEST showed remarkable percentages of inhibition. There are two distinct biphasic nociceptive responses in the formalin test. Injection of formalin produces neurogenic acute pain due its direct chemical activation of nociceptive primary afferent fibers. After certain time of formalin injection, the inflammatory pain occurs. Therefore, the test can be utilized to elucidate the potential mechanism of tested drugs. CNS acting compounds act on both phases; however, many anti-inflammatory drugs inhibit only the chronic phase [24,25].

Findings of this study suggested that MEST acts on both neurogenic and inflammatory phases. Although, the action of MEST on the inflammatory phase is more prominent, this possibly suggests the inhibitory properties of MEST on prostaglandin synthesis or release [25]. MEST was found to increase the number of writhings in acetic acid -induced writhing test suggesting the synergistic effect with acetic acid in sensitizing the nociceptors. The irritating nature of acetic acid was further augmented by MEST causing retraction of abdomen as well as stretching of hind limb. It showed that MEST had visceral pain producing properties especially in the smooth muscles. In contrast, MEST was observed to decrease the formalin induced hind paw licking in animals suggesting the decrease in the peripheral pain and sensation produced by formalin. Further study should be conducted to elucidate the exact mechanism of action of 
MEST on enhancing or decreasing the visceral and peripheral nociception.

\section{CONCLUSION}

Although, MEST alters inflammation and nociception in different animal models, the mechanisms behind theses alterations are still unknown. It was found to increase the nociception in one of the model but at the same time, it decreased the pain in another model. This variation of activity in the two nociception models could be due to influence of different constituents present within the extract. The MEST used in the present study decreased inflammation in the two models utilized here. Nevertheless, ST is known to contain a number of hazardous and carcinogenic components, including $\mathrm{N}$-nitroso compounds and benzo(a)pyrene that are classified as Class-I carcinogens. Although the plant shows some anti-inflammatory or anti-nociceptive activities, it should not be used for the purpose as the hazards due to ST outweighs the benefits.

\section{DECLARATIONS}

\section{Acknowledgement}

This work was supported by a grant from Deanship of Scientific Research (no. RG-2-9), Jazan University, Jazan, Saudi Arabia.

\section{Conflict of interests}

No conflict of interest is associated with this work.

\section{Contribution of authors}

We declare that this work was done by the author(s) named in this article and all liabilities pertaining to claims relating to the content of this article will be borne by the authors. We also declare that all authors read and approved the manuscript for publication. Hassan A. Alhazmi conceived and designed the study and overall supervision, Siddig I. Abdelwahab: Worked as a member of the research team who carried out the experimental work; also involved in analysis of data and writing the manuscript. Syam Mohan carried out the experimental work and was assisted by Manal ME Taha, Mohammad Al Bratty supervised the work and assisted in data analysis while Waquar Ahsan collected and analysed the data, and wrote the manuscript. All authors read and approved the manuscript for publication.

\section{REFERENCES}

1. Hoffmann D, Hecht SS. Nicotine-derived N-nitrosamines and tobacco-related cancer: current status and future directions. Cancer Res 1985; 45: 935-944.

2. Russo P, Nastrucci C, Alzetta G, Szalai C. Tobacco habit: historical, cultural, neurobiological, and genetic features of people's relationship with an addictive drug. Perspect Biol Med 2011; 54: 557-577.

3. Idris AM, Warnakulasuriya KA, Ibrahim YE. Toombakassociated oral mucosal lesions in Sudanese show a Iow prevalence of epithelial dysplasia. J Oral Pathol Med 1996; 25: 239-244.

4. Idris AM, Ibrahim SM, Vasstrand EN, Johannessen AC, Lillehaug JR, Magnusson B, Wallstrom M, Hirschf JM, Nilsen $R$. The Swedish snus and the Sudanese toombak: are they different? Oral Oncol 1998; 34: 558566.

5. Klus $H$, Kunze $M$, Koenig $S$, Poeschl E. Smokeless tobacco-An overview. Beitr Tabforsch Int 2009; 23: 125128.

6. Abdelwahab SI, Mohan S, Taha MME, Alsanosy RM, Karimian H. Assessment of cytotoxicity of smokeless tobacco (shammah) in Hepg2 and WRL68 cells line. Pharmacogn J 2015; 7: 242-248.

7. Peppone LJ, Mustian KM, Morrow GR, Dozier AM, Ossip $D J$, Janelsins MC, Sprod LK, Mcintosh S. The effect of cigarette smoking on cancer treatment-related side effects. Oncologist 2011; 16: 1784-1792.

8. Dwivedi S, Goel A, Mandhani A, Khattri S, Pant KK. Tobacco exposure may enhance inflammation in prostate carcinoma patients: An explorative study in north Indian population. Toxicol Int 2012; 19: 310-318.

9. Furie MB, Raffanello JA, Gergel El, Lisinski TJ, Horb LD. Extracts of smokeless tobacco induce pro-inflammatory changes in cultured human vascular endothelial cells. Immunopharmacology 2000; 47: 13-23.

10. Sharma C, Kaur J, Shishodia S, Aggarwal BB, Ralhan R. Curcumin down regulates smokeless tobacco-induced NF-Kb activation and COX-2 expression in human oral premalignant and cancer cells. Toxicology 2006; 228: 1 15.

11. Acar G, Akkoyun M, Dirnak I, Olmez S, Deniz MS, Akcay A, Ardic I, Tuncer C. Effects of smoking and smokeless tobacco "Maras powder" use on cardiac autonomic function and inflammation. J Am Coll Cardiol 2018; 62: 124-125.

12. Devi AR, Sengupta $M$, Choudhury $Y$. Aqueous extract of smokeless tobacco (gutkha) deregulates tumor suppressor and DNA repair response in a murine model of smokeless tobacco use. J Environ Pathol Toxicol Oncol 2017; 36: 245-267.

13. Sgambato JA, Sgambato JA, Jones BA, Caraway JW, Prasad GL. Inflammatory profile analysis reveals differences in cytokine expression between smokers, moist snuff users, and dual users compared to nontobacco consumers. Cytokine 2017; 6: 30355-30361. 
14. Petro TM, Schwartzbach SD, Zhang S. Smokeless tobacco and nicotine bring about excessive cytokine responses of murine memory $T$-cells. Int $J$ Immunopharmacol 1999; 21: 103-114.

15. Petro TM, Anderson LL, Gowler JS, Liu XJ, Schwartzbach SD. Smokeless tobacco extract decreases IL-12 production from LPS-stimulated but increases IL-12 from IFN-gamma-stimulated macrophages. Int J Immunopharmacol 2002; 2: 345355.

16. Bergmeyer HU, Horder M. IFCC methods for the measurement of catalytic concentration of enzymes. Part 3. IFCC method for alanine aminotransferase. $J$ Clin Chem Clin Biochem1980; 18: 521-534.

17. Odabasoglu F, Halici Z, Aygun H, Halici M, Atalay F, Cakir A, Cadirci E, Bayir Y, Suleyman H. A-Lipoic acid has anti-inflammatory and anti-oxidative properties: an experimental study in rats with carrageenan-induced acute and cotton pellet-induced chronic inflammations. Br J Nutr 2011; 105: 31-43.

18. Hosseinzadeh $H$, Younesi HM. Antinociceptive and antiinflammatory effects of Crocus sativus L. stigma and petal extracts in mice. BMC Pharmacol 2002; 2: 7.

19. Taesotikul T, Panthong A, Kanjanapothi $D$, Verpoorte $R$, Scheffer JJ. Anti-inflammatory, antipyretic and antinociceptive activities of Tabernaemontana pandacaqui Poir. J Ethnopharmacol 2003; 84: 31-35.
20. Avti PK, Kumar S, Pathak CM, Vaiphei K, Khanduja KL. Smokeless tobacco impairs the antioxidant defense in liver, lung, and kidney of rats. Toxicol Sci 2006; 89: 547553.

21. Bagchi M, Bagchi D, Hassoun EA, Stohs SJ. Subchronic effects of smokeless tobacco extract (STE) on hepatic lipid peroxidation, DNA damage and excretion of urinary metabolites in rats. Toxicology 1998; 127: 29-38.

22. Alsanosy RM. Smokeless tobacco (shammah) in Saudi Arabia: a review of its pattern of use, prevalence, and potential role in oral cancer. Asian Pac J Cancer Prev 2014; 15: 6477-6483.

23. Vishwanatha JK, Swinney R, Banerjee AG. Modulation of annexin I and cyclooxygenase-2 in smokeless tobaccoinduced inflammation and oral cancer. Mol Cell Biochem 2003; 248: 67-75.

24. Rivat C, Sar C, Mechaly I, Leyris JP, Diouloufet L, Sonrier C, Philipson Y, Lucas O, Mallié S, Jouvenel A, et al. Inhibition of neuronal FLT3 receptor tyrosine kinase alleviates peripheral neuropathic pain in mice. Nat Commun 2018; 9: 1042.

25. Shojaii A, Motaghinejada M, Norouzia S, Motevaliana M. Evaluation of anti-inflammatory and analgesic activity of the extract and fractions of astragalus hamosus in animal models. Iran J Pharm Res 2015; 14: 263-269. 